\title{
A Novel Evaporator Integrated with Wettability Pattern for Improving Thermal Performance of an Ultrathin Vapor Chamber
}

\author{
Yinchuang Yang ${ }^{1}$, Jian Li ${ }^{1}$, Dong Liao' ${ }^{1}$ Xin Ye ${ }^{1}$, Huihe Qiu, \\ ${ }^{1}$ The Hong Kong University of Science and Technology, Department of Mechanical and Aerospace Engineering \\ Clear Water Bay, Hong Kong SAR, China \\ yyangbv@connect.ust.hk; eelijian@seu.edu.cn; dliao@connect.ust.hk; xin.ye@connect.ust.hk; meqiu@ust.hk
}

\begin{abstract}
We investigated the thermal performance of a novel multiscale evaporator of a $0.23 \mathrm{~mm}$ thickness ultrathin vapor chamber which combines a microstructured wettability patterned surface with a nanostructured woven mesh wick. The microstructured wettability patterned surface underneath the nanostructured woven mesh wick can pin the three-phase contact lines on the hydrophilic/hydrophobic boundaries, enlarging the area of thin-film evaporation. Besides, the nanostructured mesh not just provides a large amount of backflow water for maintaining the evaporation on the three-phase contact lines, but also gives more thin-film evaporation area owing to its needlelike nanostructure. Microstructured wettability pattern is fabricated on the inner surface of the evaporator and the wick is pressed onto the wettability patterned surface by a micropillar array to make them close contact with each other. The micropillar array fabricated by electroplating on the inner surface of the condenser is also used to support a vapor core as a vapor flow path. The horizontal and vertical thermal resistances are measured to evaluate the thermal performance of the ultrathin vapor chamber for different charge amounts of water when the input heat flux ranges from $8.59 \mathrm{~W} / \mathrm{cm} 2$ to $23.91 \mathrm{~W} / \mathrm{cm} 2$ and the heat sink is $22{ }^{\circ} \mathrm{C}$ forced air cooling with $6.875 \mathrm{cfm}$ flow rate. The measurement results show that the novel evaporator not just greatly reduce the horizontal thermal resistance, but also lower the vertical thermal resistance compared with the evaporator without wettability pattern. The highest in-plane effectivity of the ultrathin vapor chamber with the novel evaporator can reach $11499.5 \mathrm{~W} /(\mathrm{m} \cdot \mathrm{K})$ at $23.91 \mathrm{~W} / \mathrm{cm} 2$, giving a $212.7 \%$ improvement compared with the ultrathin vapor chamber without wettability pattern on its evaporator.
\end{abstract}

Keywords: Chemically patterned surface; Ultrathin vapor chamber; Wettability; Enhance heat transfer; In-plane effective thermal conductivity

\section{Introduction}

Increasing demand of the cooling capacity for the thin electronic devices requires a heat spreader with a compact shape and powerful cooling ability. Ultrathin vapor chamber (UTVC), which utilizes the phase change of working fluid to transfer heat both in vertical and horizontal direction, becomes a promising solution for the increasing demand owing to its brilliant cooling ability. Chen et al. [1] developed a $0.4 \mathrm{~mm}$ UTVC utilizing etching and diffusion bonding for the fabrications. Huang et al. [2] adopted a composite wick structure which combines four spiral woven meshes and one bottom mesh for their UTVC, greatly enhancing the temperature uniformity across the condenser surface. Struss Q et al. [3] investigated the feasibility of an UTVC fabricated with silicon material for compact electronic cooling. Huang et al. [4] numerically analysed the heat transfer characteristic of an UTVC which utilized a multi-vapor channel with a spiral woven mesh as a composite wick. Li et al. [5] experimentally investigated the effect of vapor core thickness on UTVCs. Yu et al. [6] analysed the effect of the passage area ratio of liquid to vapor on the thermal performance of UTVC. As the thickness of UTVC commonly is less than $0.5 \mathrm{~mm}$, enhancing the thermal performance by modifications of wick structures which can cause an increase in the thickness is limited. While wettability has large effects on the evaporation and boiling, changing wettability with chemical coating to improve the thermal performance is more appreciable as it does almost not increase the thickness. Sun et al. [7] modified the condenser wettability of a vapor chamber to superhydrophobic, greatly enhancing the temperature uniformity across the condenser surface. They also made the wick structure of the vapor chamber superhydrophilic, lowering the vertical thermal resistance and increasing the critical heat flux [8]. Shaeri et al. [9] investigated the feasibility of a hydrophobic evaporator for the vapor chamber but failed to enhance the thermal performance compared with a baseline vapor chamber. Then they adopted a biphilic evaporator to the vapor chamber. Though the vapor chamber shows some enhancements 
compared with the vapor chamber with a hydrophobic evaporator, but still performed poor than the baseline vapor chamber [10].

Thin-film evaporation, occurring at the contact line of liquid, accounts for more than $50 \%$ total heat transfer in capillary wick of a two-phase heat spreader $[11,12]$. Increasing the area of thin-film evaporation by elongating the length of the contact line probably enhances the thermal performance of UTVC. In our previous research, wettability patterned surface can enhance the evaporation rate of a droplet through prolonging the length of the droplet contact line [13]. Besides, boiling which might also happened at the high heat flux in the UTVC can be also improved by the surface $[14,15]$. Therefore, integrating a wettability patterned surface on the evaporator of a vapor chamber may enhance the thermal performance of the vapor chamber. In this study, we investigated the effect of an evaporator with a wettability patterned surface on the vapor chamber, founding it enhances the thermal performance both in horizontal and vertical direction. Besides, a primary investigation on the characteristic of the wettability patterned surface is also conducted. The experimental results show that the pitch distance of nearby hydrophobic islands greatly affect the extent of the improvement for thermal performance.

\section{Fabrication of the Ultrathin Vapor Chamber and Experimental Setup \\ 2.1. Design and Fabrication of Ultrathin Vapor Chamber}

The ultrathin vapor chambers consist of three main parts, condenser with support micropillar array, multiscale micro/nanostructured mesh wick and chemically wettability patterned evaporator as shown in Figure 1(a). Copper(C1100P) plates with $30 \mu \mathrm{m}$ and $40 \mu \mathrm{m}$ thickness are selected as the bottom casing material and top casing material, respectively. Support micropillar array is fabricated on the top casing material using the method in Ref. [16]. The thickness of it defines the height of vapor core. The \#450 phosphor bronze mesh (C5191, wire diameter: $28 \mu \mathrm{m}$, wire spacing: $28 \mu \mathrm{m})$ is adopted as the wick. As shown in Figure 2(a), a needle-like nanostructure is fabricated on the surface of wick to improve capillary pressure and enlarge the evaporation rate. It is fabricated by immersing the mesh into an aqueous solution with $0.065 \mathrm{M}$ $\mathrm{K}_{2} \mathrm{~S}_{2} \mathrm{O}_{8}$ and $2.5 \mathrm{M} \mathrm{KOH}$ for 30 minutes at $70{ }^{\circ} \mathrm{C}$, followed by rinsed with deionized water and dried in a $180{ }^{\circ} \mathrm{C}$ oven for 2 hours [17].

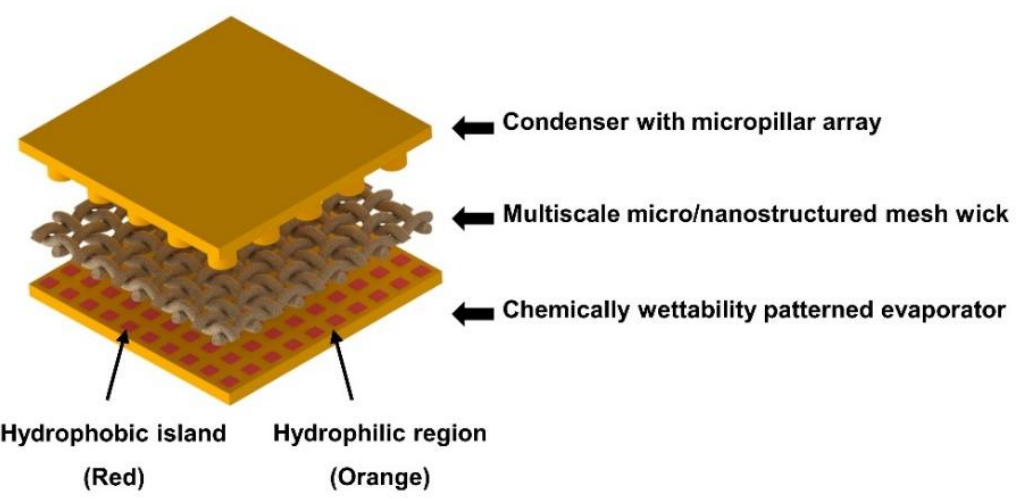

(a)

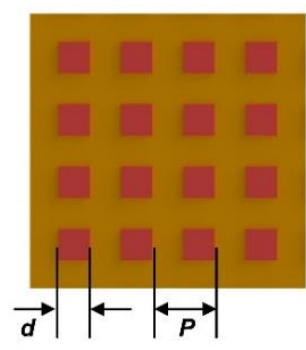

(b)

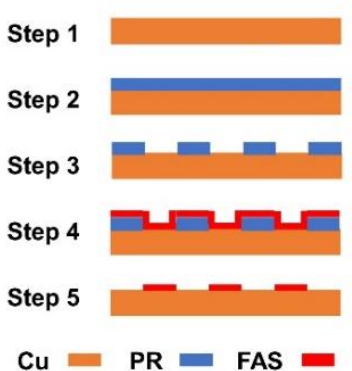

(c)

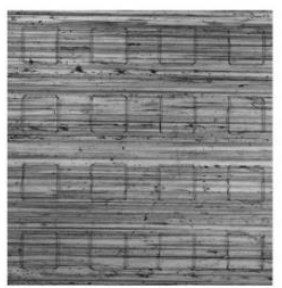

(d) 
Figure 1 (a) Schematic of vapor chamber with wettability patterned evaporator (b) Fabrication procedures of wettability patterned evaporator (c) Schematic of wettability patterned evaporator (d) Micro-view of a wettability patterned surface

To investigate the effect of chemically wettability patterned evaporators on the ultrathin vapor chambers, chemically wettability patterned surfaces with different geometry are fabricated on the inner surface of the bottom casing material, forming the evaporator of ultrathin vapor chamber. It consists of hydrophilic region and hydrophobic island, as shown in Figure 1(b). The dimension of hydrophobic island is $45 \mu \mathrm{m} \times 45 \mu \mathrm{m}$ with a square array distributed on the surface of the bottom casing material while the pitch distance between the centre of two nearby hydrophobic islands is $65 \mu \mathrm{m}$ or $90 \mu \mathrm{m}$. The procedures for fabricating the chemically wettability patterned evaporator is shown in Figure 1(c). First, copper plate is cleaned by acetone with 15 minutes ultrasonic, followed by rinsed with IPA and deionized water. After that, dilute sulfuric acid is used to remove native oxide layer on the copper surface and the copper is rinsed with deionized water again. To protect the hydrophilic region, cleaned copper with HPR506 photoresist pattern is formed by photolithography. Then it is immersed is immersed into a fluoroalkylsilane (FAS) solution and baked in a $115^{\circ} \mathrm{C}$ oven to form hydrophobic islands. The FAS solution has a mass ratio of FAS to hexane of 1.6\%. Finally, the HPR506 photoresist is removed by acetone to finish the fabrication of wettability patterned surface which is shown in Figure 1(d).

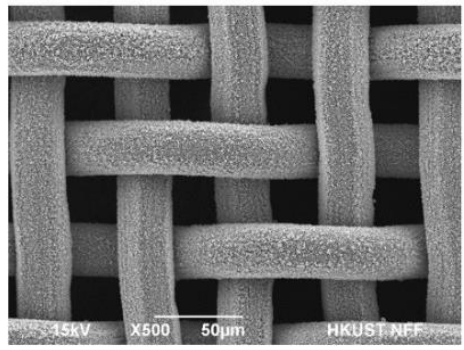

(a)

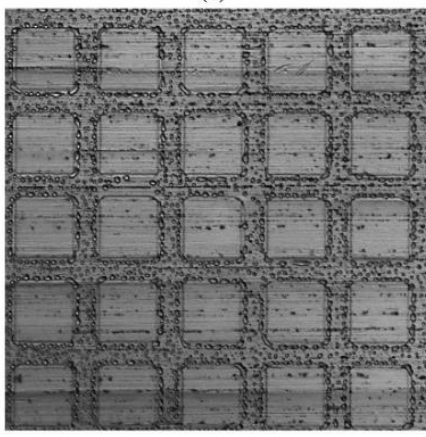

(c)

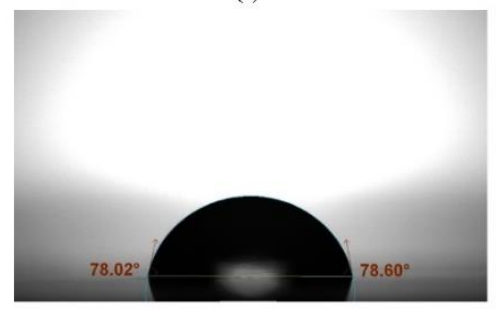

(e)

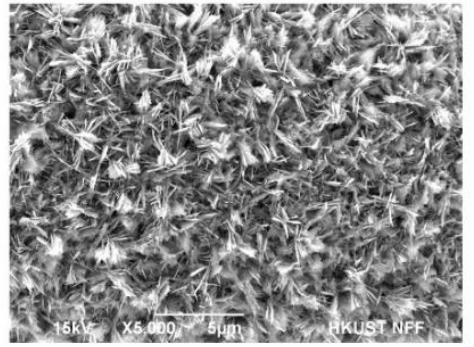

(b)

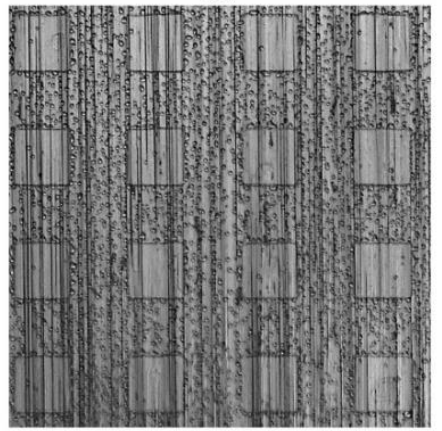

(d)

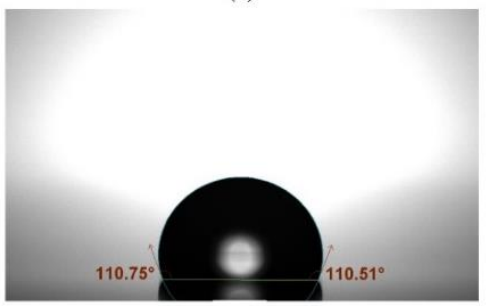

(f)

Figure 2 (a) SEM picture of nanostructured \#450 phosphor bronze mesh; (b) Amplified view of the mesh; (c) Wettability check for pattern with $65 \mu \mathrm{m}$ pitch distance; (d) Wettability check for pattern with $90 \mu \mathrm{m}$ pitch distance; (e) Water contact angle of the hydrophilic surface; (f) Water contact angle of the hydrophobic island

The wettability of the surface is checked before assembly of the ultrathin vapor chamber. The evaporator is fixed on the $10{ }^{\circ} \mathrm{C}$ stage of microscopy and monitored when a $40^{\circ} \mathrm{C}$ vapor flows pass the surface of evaporator, which is shown in Figure 
2(c) and (d), vapor condenses on hydrophilic region, proving the successful fabrication of the evaporator. As shown in Figure 2(e) and (f), the static water contact angle of the hydrophilic region and hydrophobic island are measured, which are $78^{\circ}$ and $110^{\circ}$, respectively. Then the mesh layer is sandwiched between the condenser and the evaporator, followed by sealed with $\mathrm{Sn} / 3 \mathrm{Ag} / 0.5 \mathrm{Cu}$ solder. A copper tube is inserted into the ultrathin vapor chamber to do the evacuation and filling process. The dimension of the fabricated ultrathin vapor chamber is $70 \times 70 \times 0.246 \mathrm{~mm}^{3}$ with a $60 \times 60 \mathrm{~mm}^{2}$ working area.

After the vapor chamber is assembled, a certain amount of water needs to be filled into the vapor chamber before experimental testing. Vapor chamber firstly is evacuated to $1 \mathrm{~Pa}$, followed by charged with degassed deionized water. As shown in Figure 3, the thickness of vapor chamber after evacuation and charging process is around $0.228 \mathrm{~mm}$. To evaluate the amount of water inside the vapor chamber, charge ratio is defined as following:

$$
\eta=V_{\text {water }} / V_{\text {total }} \times 100 \%
$$

where $V_{\text {water }}$ is the volume of water inside the vapor chamber and $V_{\text {total }}$ is the total volume of the vapor chamber which is $0.4545 \mathrm{ml}$. Charge ratio greatly affects the thermal performance of vapor chambers. High charge ratio increases the flow resistance of vapor by narrowing the vapor core, while small charge ratio may result in early dry out due to a lack of water. Thus, three different charge ratio, $57.2 \%, 61.6 \%$ and $66 \%$, are set to find the optimum charge ratio.

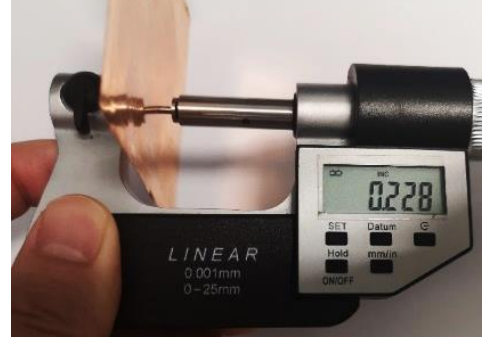

Figure 3 The thickness of an ultrathin vapor chamber after evacuation and charging process

\subsection{Experimental Setup and Uncertainty Analysis}

Figure 4 demonstrates the LW9510 (LongWin Co. Ltd.) vapor chamber thermal performance measurement apparatus used in the experiment [2]. Heat is inputted from the heater with an area of $8 \mathrm{~mm} \times 8 \mathrm{~mm}$ by an external power supply. An adjustable cooling fan is used to cooling the condenser of vapor chamber. The flow rate of the cooling air is $6.875 \mathrm{cfm}$ at 22 ${ }^{\circ} \mathrm{C}$ room temperature. Five T-type thermocouples with $0.1{ }^{\circ} \mathrm{C}$ resolution are mounted at the outside surface of the condenser and another one is inserted into the heater for temperature measurement, which are shown in Figure 4(b) and (c).

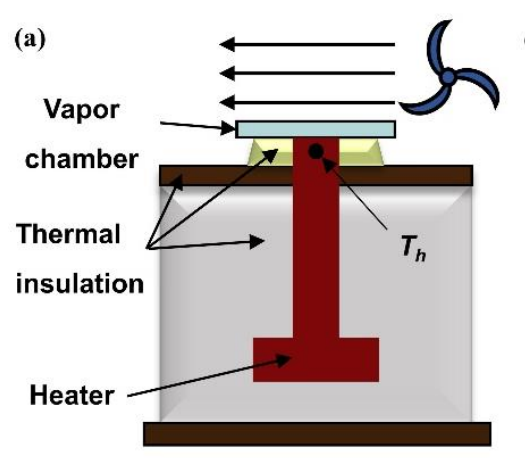

(b)

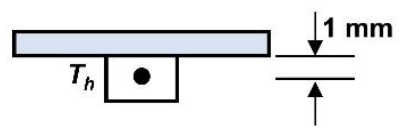

(c)

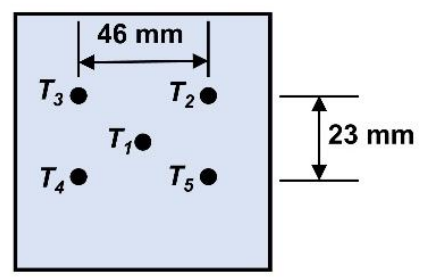

Figure 4 Experimental setup: (a) Apparatus; (b) Heater temperature measurement; (c) Temperature measurement points on the top of the vapor chamber

Thermal spreading resistance (Rspread) and vertical thermal resistance (Rvr) are defined to evaluate the thermal performance of the vapor chamber:

$$
\begin{gathered}
R_{\text {spread }}=\left(T_{1}-T_{\text {avg }(2-5))} / Q\right. \\
R_{v r}=\left(T_{b}-T_{\text {avg }(1-5)}\right) / Q
\end{gathered}
$$


where $\operatorname{Tavg}(1-5)=\left(T_{1}+T_{2}+T_{3}+T_{4}+T_{5}\right) / 5$ and $\operatorname{Tavg}(2-5)=\left(T_{2}+T_{3}+T_{4}+T_{5}\right) / 4 . T_{1}$ is the temperature at the centre of the condenser outside surface, $T_{2}, T_{3}, T_{4}$ and $T_{5}$ are the temperatures at four side measurement points (Figure 4 (c)). $Q$ is the input heat load. $T_{b}$ is the temperature at the centre of the evaporator outside surface, which can be calculated according to Fourier's law:

$$
T_{b}=T_{h}-q l / k_{C u}
$$

where $T_{h}$ is the measured heater temperature. $l$ is the distance from the thermocouple point to the heater upper surface, which is $0.001 \mathrm{~m} . \mathrm{kCu}$ is the thermal conductivity of copper, which is $401 \mathrm{~W} /(\mathrm{m} \cdot \mathrm{K}) . q$ is the input heat flux, which is:

$$
q=Q / A_{h}
$$

where $A_{h}$ is the heater area, $8 \times 8 \mathrm{~mm} 2$ in this study. As the heater is well insulated by insulation materials, the heat loss from the heater to the ambient is small, only about $0.41 \mathrm{~W}$ in the experiments.

To characterize the temperature uniformity of the vapor chamber and compare with copper, in-plane effective thermal conductivity (Keff) is defined to indicate its ability to conduct heat:

$$
K_{\text {eff }}=k_{\text {Cu }} R_{\text {Spread,Cu }} / R_{\text {Spread }}
$$

where $R_{h r, C u}$ is the measured horizontal thermal resistance of copper.

For the testing apparatus LW9510, the relative uncertainty of the heat load is $\pm 0.9 \%$, the temperature measurement uncertainty is $\pm 0.2 \%$ and the length measurement uncertainty is $\pm 0.4 \%$ [2].

\section{Result and Discussion}

\subsection{Results of Thermal Spreading Resistance}
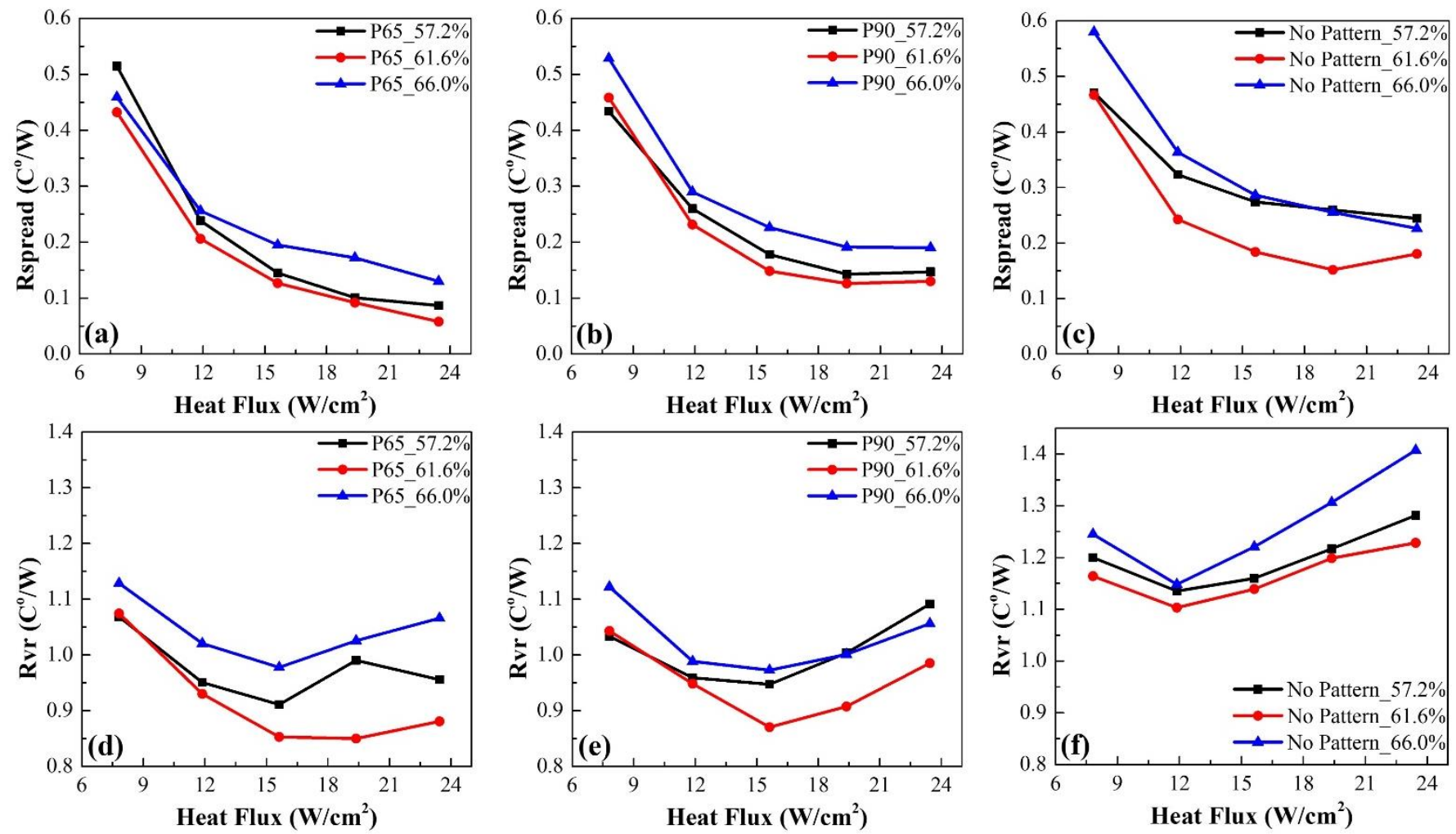

Figure 5 Thermal performance of vapor chambers with various wettability patterned evaporator: Thermal spreading resistance of (a)

D45P65, (b) D45P90 and (c) No pattern; Vertical thermal resistance of (d) D45P65, (e) D45P90 and (f) No pattern

Figure 5(a), (b) and (c) show thermal spreading resistance of ultrathin vapor chambers in this study. P65 and P90 represents an ultrathin vapor chamber with wettability patterned evaporator of $65 \mu \mathrm{m}$ and $90 \mu \mathrm{m}$ pitch distance between two 
adjacent hydrophobic islands, respectively. "No pattern" representing an ultrathin vapor chamber without wettability patterned evaporator is also experimentally evaluated. Samples with three different charge ratio is assessed firstly to find optimum charge ratio which is defined as the charge ratio where the minimum thermal resistance of sample occurs.

As shown in Figure 5(a), the thermal spreading resistance decreases with the increase of heat flux for all the charge ratio of P65. When the charge ratio is $57.2 \%$, thermal spreading resistance largely decreases from $0.515^{\circ} \mathrm{C} / \mathrm{W}$ to 0.238 ${ }^{\circ} \mathrm{C} / \mathrm{W}$ when heat flux increases from $7.81 \mathrm{~W} / \mathrm{cm}^{2}$ to $11.89 \mathrm{~W} / \mathrm{cm}^{2}$. Then it gradually decreases from $0.238^{\circ} \mathrm{C} / \mathrm{W}$ to the minimum thermal spreading resistance $0.087{ }^{\circ} \mathrm{C} / \mathrm{W}$ with the increase of heat flux from $11.89 \mathrm{~W} / \mathrm{cm}^{2}$ to $23.44 \mathrm{~W} / \mathrm{cm}^{2}$. P65 with $61.6 \%$ and $66.0 \%$ charge ratio show a similar trend with that of $57.2 \%$ charge ratio. The minimum thermal spreading resistance of $\mathrm{P} 65$ occurred at the $23.44 \mathrm{~W} / \mathrm{cm}^{2}$ of $61.6 \%$ charge ratio, which is $0.058{ }^{\circ} \mathrm{C} / \mathrm{W}$.

Figure 5(b) illustrates the thermal spreading resistance of P90. The thermal spreading resistance for all testing charge ratio also largely decreases with the heat flux increasing from $7.81 \mathrm{~W} / \mathrm{cm}^{2}$ to $11.89 \mathrm{~W} / \mathrm{cm}^{2}$, which are similar to that of P65. Then it gradually decreases as heat flux increases to $19.38 \mathrm{~W} / \mathrm{cm}^{2}$. The minimum thermal spreading resistance of $57.2 \%$ and $61.6 \%$ charge ratio occur at the heat flux of $19.38 \mathrm{~W} / \mathrm{cm}^{2}$, while for the $66.0 \%$ charge ratio, the minimum thermal spreading resistance happens at the heat flux of $23.44 \mathrm{~W} / \mathrm{cm}^{2}$. However, the thermal spreading resistance under same charge ratio at the heat flux of $19.38 \mathrm{~W} / \mathrm{cm}^{2}$ and $23.44 \mathrm{~W} / \mathrm{cm}^{2}$ are almost equal. P90 with $61.6 \%$ shows the minimum thermal spreading resistance among all the testing conditions, which is $0.126^{\circ} \mathrm{C} / \mathrm{W}$ at $19.38 \mathrm{~W} / \mathrm{cm}^{2}$.

Figure 5(c) shows the thermal spreading resistance of "No pattern". The optimum charge ratio referring to thermal spreading resistance is $61.6 \%$ as lowest thermal spreading resistance exists at $61.6 \%$ charge ratio for all the testing heat flux. The minimum thermal spreading resistance for "No pattern" is $0.152{ }^{\circ} \mathrm{C} / \mathrm{W}$ at $19.38 \mathrm{~W} / \mathrm{cm}^{2}$. The thermal spreading resistance of "No pattern" under optimum charge ratio also large decreases with the increase of heat flux from 7.81 $\mathrm{W} / \mathrm{cm}^{2}$ to $11.89 \mathrm{~W} / \mathrm{cm}^{2}$. However, it increases when the heat flux increases from $19.38 \mathrm{~W} / \mathrm{cm}^{2}$ to $23.44 \mathrm{~W} / \mathrm{cm}^{2}$, which is different from ultrathin vapor chamber with wettability patterned evaporator.

\subsection{Results of Vertical Thermal Resistance}

Figure 5(d), (e) and (f) show the vertical thermal resistance of all the testing samples. As shown in Figure 5(d), the vertical thermal resistance of P65 largely decreases when heat flux increases from $7.81 \mathrm{~W} / \mathrm{cm}^{2}$ to $15.63 \mathrm{~W} / \mathrm{cm}^{2}$ for all the charge ratios. A Minimum value of vertical thermal resistance for charge ratio of $57.2 \%$ and $66 \%$ exists at $15.63 \mathrm{~W} / \mathrm{cm}^{2}$, which is $0.911{ }^{\circ} \mathrm{C} / \mathrm{W}$ and $0.978{ }^{\circ} \mathrm{C} / \mathrm{W}$, respectively. The minimum value for $61.6 \%$ happened at $19.38 \mathrm{~W} / \mathrm{cm} 2$, which is $0.850{ }^{\circ} \mathrm{C} / \mathrm{W}$. Then the vertical thermal resistance for $61.6 \%$ and $66.0 \%$ charge ratio increases with heat flux. The vertical thermal resistance of P65 with 57.2\% charge ratio shows a different trend. It increases when heat flux increases from 15.63 $\mathrm{W} / \mathrm{cm}^{2}$ to $19.38 \mathrm{~W} / \mathrm{cm}^{2}$ then decreases again when heat flux increases from $19.38 \mathrm{~W} / \mathrm{cm}^{2}$ to $23.44 \mathrm{~W} / \mathrm{cm}^{2}$. One possible explanation for the decrease is that water vaporized much more quicker owing to the occurrence of nucleate boiling, greatly lowering the vertical thermal resistance. P65 with 61.6\% shows the lowest vertical thermal resistance among all the charge ratios. Thus, $61.6 \%$ charge ratio is the optimum charge ratio referring to the vertical thermal resistance for P65.

Figure 5(e) illustrates the vertical thermal resistance of P90. A minimum value of vertical thermal resistance for all the charge ratio exists at the $15.63 \mathrm{~W} / \mathrm{cm}^{2}$, which is $0.947{ }^{\circ} \mathrm{C} / \mathrm{W}, 0.870{ }^{\circ} \mathrm{C} / \mathrm{W}$ and $0.973{ }^{\circ} \mathrm{C} / \mathrm{W}$ for $57.2 \%, 61.6 \%$ and $66.0 \%$ charge ratio, respectively. Then the vertical thermal resistance increases with the increase of heat flux. The lowest vertical thermal resistance occurs under $61.6 \%$ charge ratio. Thus, the optimum charge ratio for P90 is $61.6 \%$.

Figure 5(f) shows the vertical thermal resistance of "No pattern". The trends of it for all the charge ratios are the same. It firstly decreases to the minimum value when heat flux increases from $7.81 \mathrm{~W} / \mathrm{cm}^{2}$ to $11.89 \mathrm{~W} / \mathrm{cm}^{2}$. Then it increases with heat flux. "No pattern" with $61.6 \%$ charge ratio shows the smallest vertical thermal resistance compared with those of other charge ratio. The lowest vertical thermal resistance is $1.139{ }^{\circ} \mathrm{C} / \mathrm{W}$, happened at $11.89 \mathrm{~W} / \mathrm{cm}^{2}$ of $61.6 \%$ charge ratio.

All samples with $61.6 \%$ charge ratio show the best thermal performance among all charge ratios. Thus, the optimum charge ratio for all samples is $61.6 \%$ In the following parts, the discussion will base on the thermal performance under the optimum charge ratio.

\subsection{Comparison of Vapor Chambers with Different Evaporators}


The best thermal performance of all samples is summarized in Figure 6. A $300 \mu \mathrm{m}$ copper plate is assessed as a reference. The in-plane effective thermal conductivity of all samples, which is shown in Figure 6(c), is calculated based on the results of thermal spreading resistance.
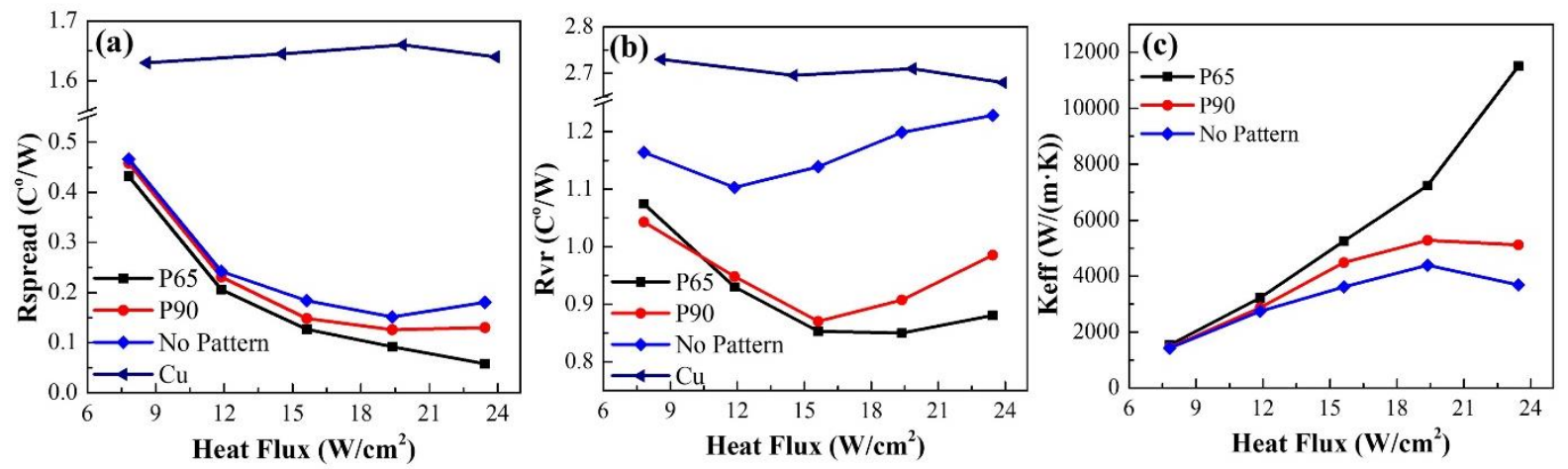

Figure 6 Comparison of ultrathin vapor chambers with various wettability patterned evaporators under optimum charge ratio: (a) Thermal spreading resistance (b) Vertical thermal resistance (c) In-plane effective thermal conductivity

The in-plane effective thermal conductivity of all samples at the heat flux of $7.81 \mathrm{~W} / \mathrm{cm}^{2}$ is similar to each other, which value is around $1500 \mathrm{~W} /(\mathrm{m} \cdot \mathrm{K})$. Vertical thermal resistance of "No pattern" is higher than that of P90 which is close to that of P65 and P90. When the heat flux increases to $11.89 \mathrm{~W} / \mathrm{cm}^{2}$, P65 shows a little higher in-plane effective thermal conductivity with a value of $3229.2 \mathrm{~W} /(\mathrm{m} \cdot \mathrm{K})$ while $\mathrm{P} 90$ and "No pattern" give a value around $2600 \mathrm{~W} /(\mathrm{m} \cdot \mathrm{K})$. $\mathrm{P} 65$ and $\mathrm{P} 90$ show a further lower vertical thermal resistance than that of "No pattern".

The difference of in-plane effective thermal conductivity between P65, P90 and "No pattern" increases when the heat flux increases to $15.63 \mathrm{~W} / \mathrm{cm}^{2}$. The in-plane effective thermal conductivity of P65 and P90 at $15.63 \mathrm{~W} / \mathrm{cm}^{2}$ are 5255.2 $\mathrm{W} /(\mathrm{m} \cdot \mathrm{K})$ and $4487.6 \mathrm{~W} /(\mathrm{m} \cdot \mathrm{K})$, respectively. However, it of "No pattern" is around $3500 \mathrm{~W} /(\mathrm{m} \cdot \mathrm{K})$. Moreover, the difference of vertical thermal resistance is also getting larger. The vertical thermal resistance difference between P90 and "No pattern" at $11.89 \mathrm{~W} / \mathrm{cm}^{2}$ is $0.155^{\circ} \mathrm{C} / \mathrm{W}$ while it at $15.63 \mathrm{~W} / \mathrm{cm}^{2}$ increases to $0.269{ }^{\circ} \mathrm{C} / \mathrm{W}$.

The in-plane effective thermal conductivity of P65 quickly increases from $5255.2 \mathrm{~W} /(\mathrm{m} \cdot \mathrm{K})$ to $11499.5 \mathrm{~W} /(\mathrm{m} \cdot \mathrm{K}) \mathrm{with}$ the increase of heat flux from $15.63 \mathrm{~W} / \mathrm{cm}^{2}$ to $23.44 \mathrm{~W} / \mathrm{cm}^{2}$ while it for other samples with wettability patterned evaporator just gradually increases even slightly decreases. P90 shows $2^{\text {nd }}$ highest in-plane effective thermal conductivity. However, the in-plane effective thermal conductivity only gradually increases within the heat flux range. "No pattern" shows the lowest in-plane effective thermal conductivity. Besides, it decreases when the heat flux increases from $19.38 \mathrm{~W} / \mathrm{cm}^{2}$ to $23.44 \mathrm{~W} / \mathrm{cm}^{2}$. As for the vertical thermal resistance, samples with wettability patterned evaporator with smaller pitch distance gives a lower vertical thermal resistance. They all perform better in vertical direction than "No pattern".

Generally, wettability patterned evaporator with smaller pitch distance gives more improvement on the thermal performance of the ultrathin vapor chamber. P65 gives the largest and P90 also shows an obvious enhancement both in thermal spreading and vertical aspects. They all give a lower thermal spreading resistance and vertical thermal resistance when compared with "No pattern".

\section{Conclusion}

A novel evaporator integrated with wettability pattern for enhancing the thermal performance of ultrathin vapor chambers is proposed in this study. Needle like nanostructured \#450 mesh is adopted as the wick and micropillar array is used to define the vapor core. Wettability patterns with various pitch distance of two adjacent hydrophobic islands are fabricated on the inner surface of the bottom casing material as an evaporator. The thermal spreading resistance and vertical thermal resistance are experimentally evaluated and analyzed. The novel evaporator not just improve the vertical thermal performance but also the horizontal thermal performance. Smaller pitch distance gives a larger enhancement of the thermal performance. With a $65 \mu \mathrm{m}$ pitch distance of the wettability patterned surface, the ultrathin vapor chamber has a 11499.5 
$\mathrm{W} /(\mathrm{m} \cdot \mathrm{K})$ in-plane effective thermal conductivity at $23.44 \mathrm{~W} / \mathrm{cm}^{2}$ heat flux, giving a $212.7 \%$ improvement when compared with the vapor chamber without the novel evaporator.

\section{Acknowledgements}

This work was supported by the Innovation Technology Commission (ITC) of the Government of the Hong Kong Special Administrative Region (HKSAR) with Project No. ITS/162/16FP, No. ITS/087/20 and the Research Grants Council of the Government of Hong Kong Special Administrative Region (HKSAR) with RGC/GRF Project No. 16205018. We acknowledge the Nanosystem Fabrication Facility (NFF) of the HKUST for the vapor chamber fabrication.

\section{References}

[1] Z. Chen, Y. Li, W. Zhou, L. Deng, and Y. Yan, "Design, fabrication and thermal performance of a novel ultra-thin vapour chamber for cooling electronic devices," Energy Conversion and Management, vol. 187, pp. 221-231, 2019.

[2] G. Huang, W. Liu, Y. Luo, and Y. Li, "A novel ultra-thin vapor chamber for heat dissipation in ultra-thin portable electronic devices," Applied Thermal Engineering, p. 114726, 2019.

[3] Q. Struss, P. Coudrain, J-P. Colonna, A. Souifi, C. Go grand, E. Deschaseaux, G. Mauguen, V. Matthieu, T. Magis, G. Simon and L. G. Frechette, "Design and fabrication of an ultra-thin silicon vapor chamber for compact electronic cooling," pp. 2259-2265, 2020.

[4] Z. Huang, X. Tang, Q. Luo, Y. Gan, J. Laing, R. Li, T. Xiong, J. Liu, L. Ma, D. Dong and Y. Li , "Numerical analysis on heat transfer characteristics of a multi-vapor channel vapor chamber with novel ultra-thin composite wick," Case Studies in Thermal Engineering, p. 101035, 2021.

[5] Y.-C. Li and S.-C. Wong, "Effects of vapor duct thickness on the capillary blocking and thermal performance of ultrathin vapor chambers under natural convection cooling," Applied Thermal Engineering, vol. 195, p. 117148, 2021.

[6] J. Yu, Y. Li, Z. Chen, Q. Luo, H. Chen, and X. Tang, "Effect of the passage area ratio of wick on an ultra-thin vapour chamber with a spiral woven mesh wick," Applied Thermal Engineering, p. 117282, 2021.

[7] Z. Sun, X. Chen, and H. Qiu, "Experimental investigation of a novel asymmetric heat spreader with nanostructure surfaces," Experimental thermal and fluid science, vol. 52, pp. 197-204, 2014.

[8] Z. Sun and H. Qiu, "An asymmetrical vapor chamber with multiscale micro/nanostructured surfaces," International Communications in Heat and Mass Transfer, vol. 58, pp. 40-44, 2014.

[9] M. R. Shaeri, D. Attinger, and R. Bonner, "Feasibility study of a vapor chamber with a hydrophobic evaporator substrate in high heat flux applications," International Communications in Heat and Mass Transfer, vol. 86, pp. 199-205, 2017.

[10] M. R. Shaeri, D. Attinger, and R. W. Bonner, "Vapor chambers with hydrophobic and biphilic evaporators in moderate to high heat flux applications," Applied Thermal Engineering, vol. 130, pp. 83-92, 2018.

[11] R. Ranjan, J. Y. Murthy, and S. V. Garimella, "A microscale model for thin-film evaporation in capillary wick structures," International Journal of Heat and Mass Transfer, vol. 54, no. 1-3, pp. 169-179, 2011.

[12] H. Wang, S. V. Garimella, and J. Y. Murthy, "Characteristics of an evaporating thin film in a microchannel," International Journal of Heat and Mass Transfer, vol. 50, no. 19-20, pp. 3933-3942, 2007.

[13] M. He, D. Liao, and H. Qiu, "Multicomponent Droplet Evaporation on Chemical Micro-Patterned Surfaces," Sci Rep, vol. 7, p. 41897, Feb 032017.

[14] A. R. Betz, J. Xu, H. Qiu, and D. Attinger, "Do surfaces with mixed hydrophilic and hydrophobic areas enhance pool boiling?," Applied Physics Letters, vol. 97, no. 14, p. 141909, 2010.

[15] H. Wang, Y. Yang, M. He, and H. Qiu, "Subcooled flow boiling heat transfer in a microchannel with chemically patterned surfaces," International Journal of Heat and Mass Transfer, vol. 140, pp. 587-597, 2019.

[16] Y. Yang, D. Liao, H. Wang, J. Qu, J. Li, and H. Qiu, "Development of Ultrathin Thermal Ground Plane with Multiscale Micro/Nanostructured Wicks," Case Studies in Thermal Engineering, p. 100738, 2020.

[17] X. Zhang, Y.-G. Guo, W.-M. Liu, and J.-C. Hao, "CuO three-dimensional flowerlike nanostructures: Controlled synthesis and characterization," Journal of Applied Physics, vol. 103, no. 11, p. 114304, 2008. 
HTFF 144-9 